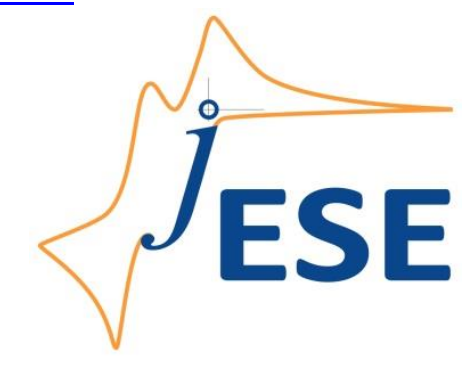

Open Access : : ISSN 1847-9286

Review Paper

\title{
A review of the electrochemical corrosion of metals in choline chloride based deep eutectic solvents
}

\author{
Mihael Bučko ${ }^{\bowtie}$ and Jelena B. Bajat ${ }^{1}$ \\ University of Defence, Military Academy, 33 Pavla Jurišića Šturma St, 11000 Belgrade, Serbia \\ ${ }^{1}$ Faculty of Technology and Metallurgy, University of Belgrade, Karnegijeva 4, 11120 Belgrade, \\ Serbia \\ Corresponding author: ${ }^{\bowtie}$ mbucko@tmf.bg.ac.rs; Tel.: +381-11-3603-464; Fax: +381-11-3603-065
}

Received: October 19 2021; Accepted: November 3, 2021; Published: November 13, 2021

\begin{abstract}
Deep eutectic solvents (DESs) are a class of mixtures with melting points notably lower than those of their raw constituent components. These liquids have found a tremendously wide spectrum of applications in the last two decades of their research, so their contact and interaction with technical metals and alloys are inevitable. Therefore, the corrosivity of DESS towards metals is an extremely important topic. This review summarizes research efforts collected in the last two decades related to the corrosion rate of various metals in different DESs. Since the DESs are mainly composed of organic raw compounds, and by their physicochemical properties they may be regarded as a separate class of ionic liquids, the literature data about DESs corrosivity has been compared to the data related to the corrosivity of various organic solvents and ionic liquids as well. All the results gained until now show significantly low corrosivity of DESs. This observation is discussed in relation to the chemical composition of DESs. The absence of the oxidizing agents, the inhibitory action of organic ions and molecules, high viscosity and low electrical conductivity have been recognized as the main factors contributing to the low metal corrosion rate in DESs.
\end{abstract}

\section{Keywords}

ionic liquids; ethaline; reline; glyceline; hydrogen bond donor

\section{Contents}

1. Introduction

2. Chemical composition of deep eutectic solvents

3. Protic character od DESs

4. High concentration of ligands in DESs

5. Electrochemical tests and measured corrosion rates in DESs

6. Effect of water content

7. Conclusion 


\section{Introduction}

Deep eutectic solvents (DESs) refer to mixtures of two or three solid or liquid compounds in a eutectic composition, where an unusually deep melting point depression is observed [1,2]. The preparation of DESs usually consists of simple mixing of the two components for several hours at a slightly elevated temperature until the homogeneous liquid is obtained (Figure 1). The main characteristic of DESs is that they are in a liquid state at room or slightly elevated temperatures [3]. Although they may not be considered ionic liquids, the DESs share many physical characteristics, such as relatively high viscosity and density, low electrolytic conductivity compared to aqueous solutions, low volatility and vapour pressure, and high thermal stability. These attributes make DESs good candidates for the replacement of traditional volatile organic solvents in many industries [4]. In addition, the DESs have some beneficial features compared to conventional ionic liquids: they are usually composed of inexpensive, widely available compounds that are biodegradable and nontoxic [5].

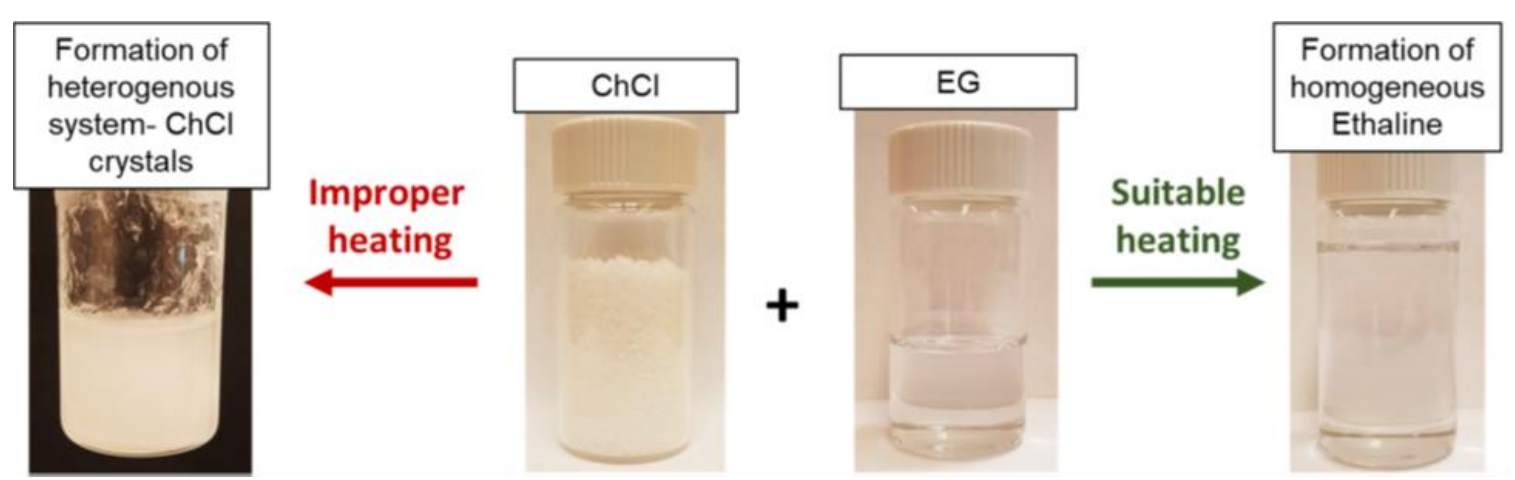

Figure 1. Preparation of ethaline: dried choline chloride and ethylene glycol are mixed in a controlled atmosphere (Ar-filled glovebox), heated to $80^{\circ} \mathrm{C}$ for 2 hours, then cooled to room temperature. Improper heating can lead to the formation of choline chloride crystals (i.e., precipitation from solution) [6]. Reprinted with permission from ref. [6], copyright (2019), American Chemical Society

During the last two decades, DESs have been involved in various applications, the most important being: dissolution of metal oxides and salts in metallurgy [7]; electrolytes in metal and alloy electroplating [8,9]; liquid-liquid extraction [10]; metal extraction [11]; gas solubility and capture [12]; electrolytes in batteries [13] or solar cells [14]; biocatalysis [15]; extraction and preparation of biodiesel [16]; biomass processing [17]; biomolecular structure stabilization [18]; genomics [19]; pharmaceutical and medical applications [20]; nanomaterials synthesis [21].

The DESs have been particularly recognized as a convenient way to extend the range of coating/substrate combinations that may be produced by the electrodeposition process, in comparison to the existing electroplating processes in water-based baths [22-24]. For example, the DESs may be an alternative for the electroplating of metals having electroreduction potential more negative to the potential of water decomposition, such as $\mathrm{Ti}, \mathrm{Al}$, and $\mathrm{W}[22,25,26]$. Furthermore, the electroplating in DESs may afford the replacement of the electroplating systems known to be toxic and carcinogenic, such as $\mathrm{Cr}, \mathrm{Ni}$ and $\mathrm{Co}[9,23,25,27]$. Figure 2 illustrates an example of the surfacesensitive $\mathrm{Ni}$ electrodeposition at $\mathrm{Pt}(111)$ single crystal surface, from choline chloride + urea DES (reline) [9]. The number of pure metal and alloy coatings that have already been successfully obtained by electrodeposition in DESs is significant, so here only the most important examples are mentioned, including corrosion-resistant coatings like $\mathrm{Cu}$ [28-31] and $\mathrm{Zn}$-alloys [32], magnetic alloys like Sm-Co [33,34], semiconducting alloys like $\mathrm{CuGaSe}_{2}$ [35], electrocatalytic surface alloys like PtCo [36], etc. 


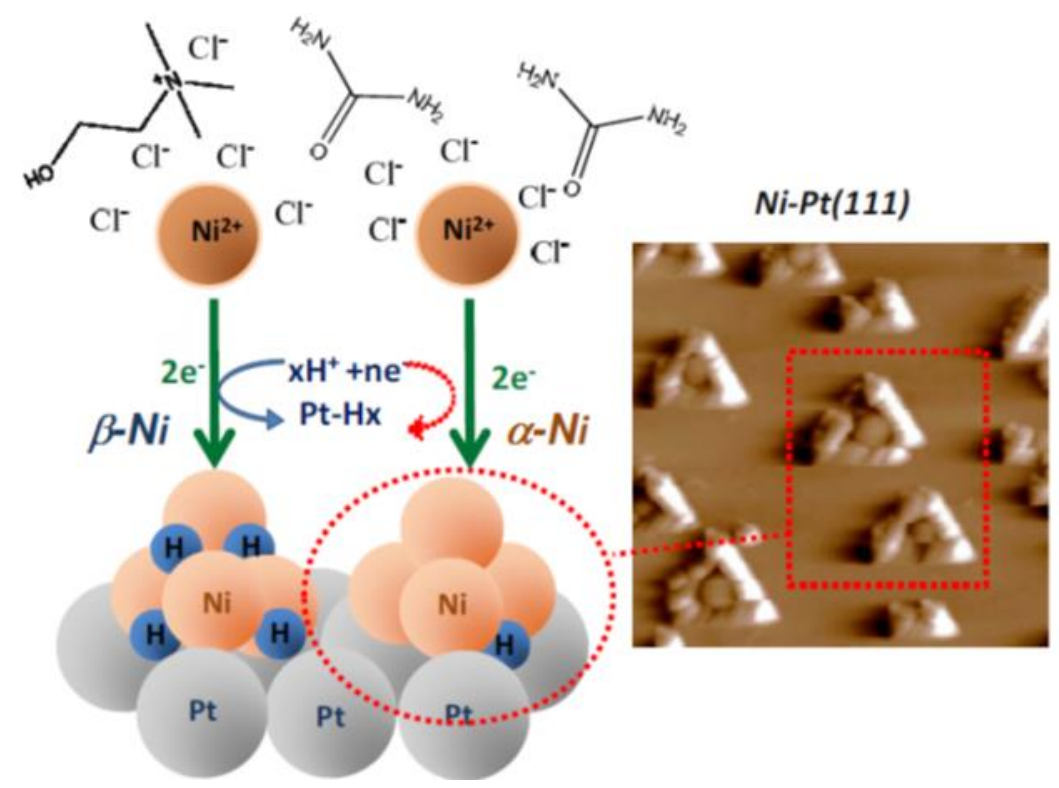

Figure 2. Representation of Ni(II) electrodeposition in DES on Pt(111) and AFM image $\left(2 \times 2 \mu m^{2}\right)$ of Ni clusters [9] Reprinted with permission from ref. [9] copyright (2018), American Chemical Society

To apply deep eutectic solvents in any large-scale process, it is important to gain knowledge about their corrosivity and interaction with different materials, particularly technical metals and alloys. This article first addresses the important features of the DESs chemical composition: their protic/aprotic character and the presence of strong complexing agents. It further recaps the data related to the metal corrosion rates collected in various DESs and by different measuring methods. Finally, it summarizes the most relevant factors responsible for a generally low corrosion rate in DESs.

\section{Chemical composition of deep eutectic solvents}

A mixture of any two compounds that exhibits a deep melting temperature decrease at the eutectic ratio of the two components may be regarded as a DES. Up to now, various DESs have been prepared by combining a quaternary ammonium salt, a metal salt or a metal salt hydrate, and a hydrogen bond donor (HBD), usually an organic molecule such as an amide, carboxylic acid, or polyol [2]. Table 1 explains the classification of DESs into five types according to their components $[4,22,37]$ :

Table 1. Five types of deep eutectic solvents

\begin{tabular}{lccc}
\hline & Metal salt & Metal salt hydrate & $\begin{array}{c}\text { Organic molecule } \\
\text { as HBD }\end{array}$ \\
\hline Quaternary ammonium salt & Type 1 & Type 2 & Type 3 \\
\hline Metal salt hydrate & & & Type 4 \\
\hline Organic molecule as hydrogen bond acceptor (HBA) & & & Type 5 \\
\hline
\end{tabular}

It is estimated [38] that there may be $10^{6}-10^{8}$ potential DES formulations as various binary combinations of ammonium salts, metal salts, and organic molecules. Since the majority of DESs contain an organic compound as one of the constituents, to predict the corrosivity of a particular $D E S$, it is advisable to first analyse the metal corrosion in a particular organic, since the literature about this topic is usually vastly available [39].

Interestingly, up to now, only the metal and alloy corrosion in the Type 3 DESs has been studied, and particularly in DESs containing choline chloride as a quaternary ammonium salt, and as a result, this review focuses primarily on the metal corrosion in Type 3 DESs. 


\section{Protic character of DESs}

Metals with the corrosion potential more negative than the equilibrium potential of hydrogen electrode corrode with the electroreduction of hydrogen proton. The presence of solvated hydrogen proton in protic organic media thus induces corrosion of electronegative metals [39]. It should be held in mind that the most frequently used HBDs in Type 3 DESs (alcohols, amides and carboxylic acids) are protic organic compounds, and so the presence of free hydrogen ions may be expected in these DESs.

The $\mathrm{pH}$ value of a DES depends on the ability of the DES's cation, anion, and HBD to act as proton acceptors and proton donors $[40,41]$. If $H A$ is a protic hydrogen bond donor, then the protonation reaction in DES is

$$
\mathrm{HA}+\mathrm{Y} \rightleftharpoons \mathrm{HY}^{+}+\mathrm{A}^{-}
$$

where $Y$ represents the DES constituent $[40,41]$.

Metal corrosion may occur due to the partial cathodic reaction of the protonated species

$$
2 \mathrm{HY}^{+}+2 \mathrm{e}^{-} \rightarrow 2 \mathrm{Y}+\mathrm{H}_{2}
$$

but also, as it is often the case in organic solutions, due to the direct hydrogen evolution from the non-dissociated proton donor [42]:

$$
2 \mathrm{HA}+2 \mathrm{e}^{-} \rightarrow 2 \mathrm{~A}^{-}+\mathrm{H}_{2}
$$

The experimentally determined $\mathrm{pH}$ values of a few representative choline chloride based Type 3 DESs are listed in Table 2. The $\mathrm{pH}$ value of $\mathrm{ChCl}$ based DESs is significantly influenced by the type of HBD. The acidity decreases in the following order: DESs with carboxylic acids (citric, glycolic, lactic, malic, malonic, oxalic acid)>polyols (ethylene glycol, glycerol) > sugars(fructose, glucose) > amines and amides (urea, ethanolamine, diethanolamine) [41]. For all choline chloride based DESs, a linear decrease of $\mathrm{pH}$ value was observed with the increase in temperature, and as concerning the water influence, the increase in water content decreases the $\mathrm{pH}$ for the majority of DESs. However, there are DESs where the opposite was observed, for instance in ChCl-citric acid mixture [41].

Table 2. Experimentally measured $\mathrm{pH}$ values of several DESS

\begin{tabular}{|c|c|c|}
\hline DES & $\mathrm{pH}$ value & Reference \\
\hline $1 \mathrm{ChCl}: 1$ oxalic acid & 1.32 & {$[43]$} \\
\hline $1 \mathrm{ChCl}: 1$ malonic acid & 2.39 & {$[43]$} \\
\hline $1 \mathrm{ChCl}: 1$ citric acid : $3 \mathrm{H}_{2} \mathrm{O}$ & $0.63-0.67$ & {$[44]$} \\
\hline \multirow{3}{*}{$1 \mathrm{ChCl}: 2$ ethylene glycol } & 4.77 & {$[45]$} \\
& 5.93 (pH indicator) & {$[43]$} \\
& $6.89(\mathrm{pH}$ glass electrode) & {$[43]$} \\
\hline \multirow{2}{*}{$1 \mathrm{ChCl}: 2$ glycerol } & 7.54 & {$[46]$} \\
& 7.48 & {$[43]$} \\
\hline \multirow{2}{*}{$1 \mathrm{ChCl}: 2$ urea } & 10.39 & {$[46]$} \\
& 10.07 & {$[47]$} \\
\hline
\end{tabular}

The fast metal corrosion due to the rapid hydrogen evolution reaction in acidic DESs was demonstrated by Abbott et al. [48], where it was shown that the corrosion rate (expressed in $\mu \mathrm{m}$ per year) for mild steel in oxaline was two orders of magnitude higher in comparison to reline and ethaline, whereas it was one order of magnitude higher for Ni. Interestingly, the corrosion rate of $\mathrm{Al}$ was low and very similar in both acidic and $\mathrm{pH}$ neutral DESs, probably due to the Al passivation by oxalate anion [48]. High acidity of an organic acid containing DESs is beneficial for the dissolution 
of various metal oxides in industrial and recycling processes because the hydrogen protons act as oxygen acceptors and break the metal-oxide bonds [49].

\section{High concentration of ligands in DESs}

Choline chloride based DESs contain $\sim 5 \mathrm{~mol} \mathrm{dm}^{-3}$ chloride anions, and these species are well known to be detrimental for metal corrosion in two ways. Firstly, the chloride ions cause the metal oxide film rupture and pitting corrosion. According to the kinetic model of pitting corrosion, the pit initiation starts with the adsorption of chloride ions on the metal oxide surface and their penetration through the oxide film and propagates with the localized dissolution of metal at the metal/oxide interface $[50,51]$. Secondly, chloride is a ligand that forms complex salts with metal ions, increasing the solubility of metal ions and metal compounds, preventing metal passivation, and displacing the redox electrode potential of the metal to the negative side, making its anodic dissolution easier [52]. As a matter of fact, since the 1990s the halide salts have been used as ligands to promote metal solubility in organic solvents [53].

The catalytic role of chloride anion in the anodic partial reaction of a metal corrosion process is well known for aqueous media, for example, in the cases of copper and steel corrosion [54,55]. It is assumed that the first step in the metal anodic dissolution mechanism is one of the following reactions:

$$
\begin{aligned}
& \mathrm{Cu}+\mathrm{Cl}^{-} \rightleftharpoons \mathrm{CuCl}+\mathrm{e}^{-} \\
& \mathrm{CuCl}+\mathrm{Cl}^{-} \rightleftharpoons \mathrm{CuCl}_{2}^{-} \\
& \mathrm{Cu}+2 \mathrm{Cl}^{-} \rightleftharpoons \mathrm{CuCl}_{2}^{-}+2 \mathrm{e}^{-} \\
& \mathrm{Fe}+\mathrm{Cl}^{-} \rightleftharpoons \mathrm{FeCl}+\mathrm{e}^{-} \\
& \mathrm{FeCl} \rightleftharpoons \mathrm{Fe}^{+}+\mathrm{Cl}^{-}
\end{aligned}
$$

The identical participation of $\mathrm{Cl}^{-}$is also very likely present in the metal dissolution process in DESs $[28,56]$. Furthermore, by identifying $\mathrm{FeOCl}$ in the corrosion products at steel immersed in ethaline and reline, Kityk et al. [56] concluded that the chloride ion present in large concentrations even changes the mechanism and accelerates steel corrosion in DES, in comparison to water solution. Particularly, $\mathrm{Cl}^{-}$ions enable the formation of $\mathrm{FeOCl}$, an intermediate compound that facilitates the formation of $y$-FeOOH [56].

Due to the high $\mathrm{Cl}^{-}$concentration in DESs, the majority of metal ions are solvated in DESs in the form of various chloro-complexes. The metal speciation was studied in DES mixtures of choline chloride with several HBDs (urea, ethylene glycol, propylene glycol, and 1,3-propanediol), by dissolving various metal salts, namely sulphates, nitrates, oxides, thiocyanates, and perchlorates [57]. It was found that $\mathrm{M}^{+}$ions form $\left[\mathrm{MCl}_{2}\right]^{-}$and $\left[\mathrm{MCl}_{3}\right]^{2-}$ species and/or their mixtures, depending on the HBD present, for instance $\left[\mathrm{CuCl}_{2}\right]^{-}$and $\left[\mathrm{CuCl}_{3}\right]^{2-},\left[\mathrm{AgCl}_{2}\right]^{-}$and $\left[\mathrm{AgCl}_{3}\right]^{2-},\left[\mathrm{AuCl}_{3}\right]^{2-}$, etc. This speciation is consistent with the chemistry in aqueous solutions with high chloride concentrations [58].

As concerning $\mathrm{M}(\mathrm{II})$ salts, in diol-based DESs all $\mathrm{M}^{2+}$ ions, except $\mathrm{Ni}^{2+}$, form tetrachloro complexes $\left[\mathrm{MCl}_{4}\right]^{2-}$, like for example, $\left[\mathrm{FeCl}_{4}\right]^{2-},\left[\mathrm{ZnCl}_{4}\right]^{2-},\left[\mathrm{PtCl}_{4}\right]^{2-}$, etc. Interestingly, chloride was not found in the $\mathrm{Ni}^{2+}$ coordination shell, but rather only the $\left[\mathrm{Ni}(\mathrm{HBD})_{3}\right]^{2+}$ cationic complexes were detected [57]. Contrary to the diol based DESs, in urea-based DES, the complex ion composition depends on the metal: the late transition metals form tetrachloro complex anions, but early transition metals like $\mathrm{Fe}, \mathrm{Mn}$ and $\mathrm{Cr}$, form salts with $\mathrm{HBD}$ as a ligand, where $\mathrm{HBD}$ may be water or urea, i.e., $\left[\mathrm{Mn}(\mathrm{HBD})_{6}\right]^{2+}$, $\left[\mathrm{Fe}(\mathrm{HBD})_{5}\right]^{2+}$ and $\left[\mathrm{CoCl}_{3}(\mathrm{HBD})\right]^{-}[57]$. 
Among $\mathrm{M}(\mathrm{III})$ salts, the experiments with $\mathrm{Cr}^{3+}$ in the same study [57] showed that in ethylene glycol-based DES, chromium forms complex salt with mixed ligands $\left[\mathrm{Cr}\left(\mathrm{H}_{2} \mathrm{O}\right)_{2} \mathrm{Cl}_{4}\right]^{2-}$, and in ureabased DES, the first shell consists only of $\mathrm{HBD}$, i.e. $\left[\mathrm{Cr}(\mathrm{HBD})_{6}\right]^{3+}$.

Dissimilar metal speciation in DESs compared to water is responsible for the difference in the electrochemical series, i.e., the series of equilibrium electrode potentials for redox reactions of various metal/metal ion couples in different media. Electrode potentials for some redox couples in ethaline were reported [59] and compared to the analogous values in an aqueous, metal chloride containing medium. It was apparent that some equilibrium electrode potentials were positive, while others were more negative compared to the values measured in water. For the redox couples with more negative potential in ethaline, the redox equilibrium in ethaline is shifted to the species with a higher oxidation state compared to the equilibrium in water, and the reverse is true for the couples above the line. It was noticeable that for metals that form strong chloro-complex ions ( $\mathrm{Au}, \mathrm{Pd}, \mathrm{Ag}$ ), there was a significant negative deviation of the equilibrium redox potential in ethaline. An interesting case was observed for $\mathrm{Cu}$ : the equilibrium potential for the redox couple $\mathrm{Cu}^{+} / \mathrm{Cu}$ is surprisingly negative in ethaline. However, the potential of the $\mathrm{Cu}^{2+} / \mathrm{Cu}^{+}$couple is very positive, pointing to the fact that in ethaline, the $\mathrm{Cu}^{+}$species is stable along with $\mathrm{Cu}$ and $\mathrm{Cu}^{2+}[59]$.

Interesting investigations of $\mathrm{Cu}$ corrosion in ethaline show that $\mathrm{Cu}$ dissolution is accelerated when $\mathrm{Cu}^{2+}$ species are present in the medium due to the comproportionation reaction (Eq. 9).

$$
\mathrm{CuCl}_{4}^{2-}+\mathrm{Cu} \rightarrow 2 \mathrm{CuCl}_{2}^{-}
$$

This reaction is well known in chloride-containing aqueous media, and it seems that the analogous mechanism may be applied for the case of ethaline $[28,29]$. The consequence of this reaction is observed in the electrodeposition process with $\mathrm{Cu}$ soluble anode, where the so-called "anomalous dissolution" occurs, i.e., the mass loss of $\mathrm{Cu}$ anode is much higher than anticipated based on the amount of charge passed for a single electron transfer. In other words, in case $\mathrm{Cu}^{2+}$ is present in ethaline, the anodic dissolution processes occurring at the $\mathrm{Cu}$ anode to form $\mathrm{CuCl}_{2}{ }^{-}$are coupled with the cathodic process involving the reduction of $\mathrm{CuCl}_{4}{ }^{2-}[28,29]$.

\section{Electrochemical tests and measured corrosion rates in DESs}

The corrosion rate of various metals in choline chloride-based DESs has been analysed by electrochemical methods in majority of the previous studies, and the reported data are summarized in Table 3. For nearly $\mathrm{pH}$ neutral DESs, i.e., with the exception of acidic DESs, generally, it may be concluded that all the sources report significantly low corrosion rates, ranging from around $1 \mu \mathrm{A} \mathrm{cm}^{-2}$ to extremely low values of the order of $\mathrm{nA} \mathrm{cm}^{-2}$. For example, the comparison of the surface morphology of Al alloy samples exposed to the air and to reline at $60^{\circ} \mathrm{C}$ for 19 days (Figure 3) showed that all the samples were shiny. The brownish deposits at the samples immersed in reline, were not corrosion products or signs of pitting, but rather only reline deposits not removed by the washing process [60].

Except for the results reported in [63], the DESs were reported as of very low corrosivity to various metals, in practically all of the conducted studies available in the literature, in spite of containing strong ligands in high concentration. The $\mathrm{Cu}$ dissolution in [63] was promoted by the rotation of the working electrode and the ultrasonic agitation to enhance metal leaching in ethaline. Therefore, it is understandable that the corrosion rate in such working conditions is significantly higher than the values measured in stationary conditions. 

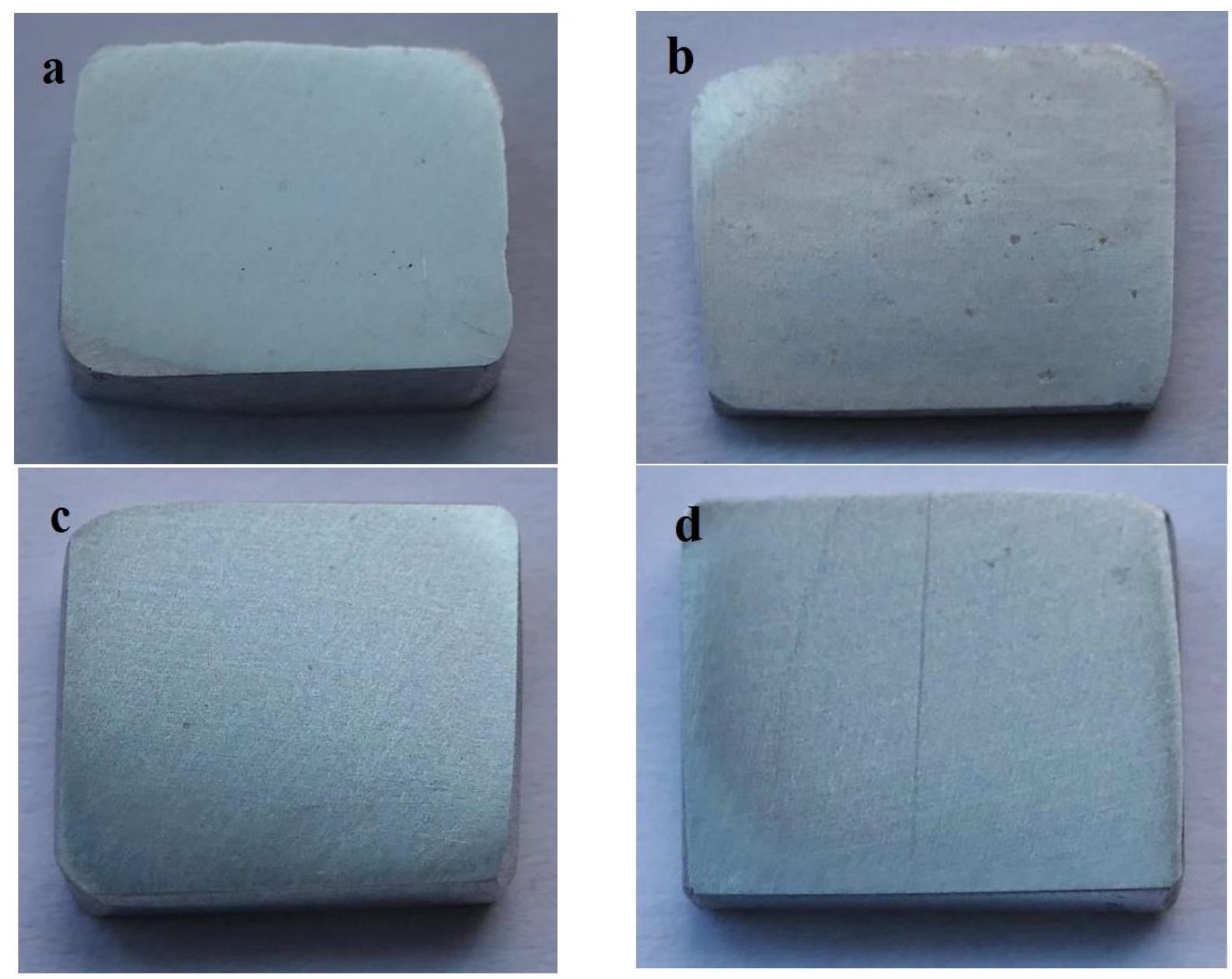

Figure 3. Visual inspection of the alloy samples after 19 days: (a,c) AA2024-T6, AA6065-T6 in the air; (b,d) AA2024-T6, AA6065-T6 in reline, respectively [60] Reprinted with permission from ref. [60] copyright (2020), Elsevier

Very low corrosivity of DESs had been ascribed to the absence of an oxidizing species in DESs, high viscosity and low electrical conductivity of DESs, the formation of a protective layer at the metal surface immersed in DES, or the inhibiting action of the constituting compounds in DESs [48,56,60-62].

The chemical corrosion of a metal in a corrosive medium implies the reaction of metal with species $\mathrm{X}$ and the formation of corrosion product:

$M+X \rightarrow M X$

In analogy, electrochemical corrosion implies the transfer of electrons from a metal surface to the corrosion agent, i.e., to the species in a corrosive medium capable of metal oxidation:

$$
\begin{aligned}
& M \rightarrow M^{n+}+n^{-} \\
& \mathrm{ne}^{-}+\mathrm{X} \rightarrow \mathrm{X}^{\mathrm{n}-}
\end{aligned}
$$

The well-known corrosion agents in aqueous media are water molecules, oxygen molecules, and hydrogen ions. Understandably, if these species are present as impurities in non-aqueous media, they also may act as agents inducing metal corrosion.

Yet, in case that the liquid medium does not contain any compound that can act as a corrosion agent for metal, the medium remains chemically inert and the metal corrosion does not occur.

It has been stated $[52,56,60]$ that apart from oxygen and water present as impurities, the $\mathrm{pH}$ neutral choline chloride based DESs do not contain any other species capable of metal oxidation. To support this statement, it is useful to tackle the oxidizing power of the organic compounds representing the most often used constituents in DESs. 
Table 3. Corrosion rate data for several DESs.

\begin{tabular}{|c|c|c|c|}
\hline Metal & DES & $j_{\text {corr }} / \mu \mathrm{A} \mathrm{cm} \mathrm{cm}^{-2}$ & testing method, reference \\
\hline \multirow{2}{*}{ steel } & \multirow{2}{*}{ reline } & 0.87 at $25^{\circ} \mathrm{C}$ & \multirow{2}{*}{ Tafel plots, [56] } \\
\hline & & 1.72 at $80^{\circ} \mathrm{C}$ & \\
\hline & \multirow{2}{*}{ reline } & $10^{-3}$ at $25^{\circ} \mathrm{C}$ & \multirow{2}{*}{ Tafel plots, [61] } \\
\hline & & 0.02 at $75^{\circ} \mathrm{C}$ & \\
\hline & \multirow{2}{*}{ ethaline } & 1.18 at $25^{\circ} \mathrm{C}$ & \multirow{2}{*}{ Tafel plots, [56] } \\
\hline & & 1.78 at $80^{\circ} \mathrm{C}$ & \\
\hline & \multirow{2}{*}{ ethaline } & 0.2 at $25^{\circ} \mathrm{C}$ & \multirow{2}{*}{ Tafel plots, [61] } \\
\hline & & 3.9 at $75^{\circ} \mathrm{C}$ & \\
\hline & \multirow{2}{*}{ glyceline } & $610^{-3}$ at $25^{\circ} \mathrm{C}$ & \multirow{2}{*}{ Tafel plots, [61] } \\
\hline & & 0.52 at $75^{\circ} \mathrm{C}$ & \\
\hline & \multirow{2}{*}{ ChCl-malonic acid } & 5 at $25^{\circ} \mathrm{C}$ & \multirow{2}{*}{ Tafel plots, [61] } \\
\hline & & 187 at $75^{\circ} \mathrm{C}$ & \\
\hline \multirow{13}{*}{ copper } & \multirow{2}{*}{ reline } & 3.58 at $25^{\circ} \mathrm{C}$ & \multirow{2}{*}{ Tafel plots, [61] } \\
\hline & & 30.45 at $75^{\circ} \mathrm{C}$ & \\
\hline & reline & 340 at $80^{\circ} \mathrm{C}$ & Tafel plots, [62] \\
\hline & \multirow{2}{*}{ ethaline } & 17.44 at $25^{\circ} \mathrm{C}$ & \multirow{2}{*}{ Tafel plots, [61] } \\
\hline & & 166.53 at $75^{\circ} \mathrm{C}$ & \\
\hline & \multirow{3}{*}{ ethaline } & 460 at $50^{\circ} \mathrm{C}$ & Tafel plots, RDE 5000 rpm [63] \\
\hline & & 8700 at $50^{\circ} \mathrm{C}$ & Tafel plots, ultrasonic agitation (US) [63] \\
\hline & & 27540 at $50{ }^{\circ} \mathrm{C}$ & Tafel plots, RDE 5000 rpm + US [63] \\
\hline & \multirow{2}{*}{ Glyceline } & 6.03 at $25^{\circ} \mathrm{C}$ & \multirow{2}{*}{ Tafel plots, [61] } \\
\hline & & 31.22 at $75^{\circ} \mathrm{C}$ & \\
\hline & \multirow{2}{*}{ ChCl-malonic acid } & 7.43 at $25^{\circ} \mathrm{C}$ & \multirow{2}{*}{ Tafel plots, [61] } \\
\hline & & 333.17 at $75^{\circ} \mathrm{C}$ & \\
\hline & \multirow{2}{*}{ Reline } & $8 \times 10^{-3}$ at $25^{\circ} \mathrm{C}$ & \multirow{2}{*}{ Tafel plots, [61] } \\
\hline \multirow{7}{*}{ Stainless steel 316} & & 0.013 at $75^{\circ} \mathrm{C}$ & \\
\hline & \multirow{2}{*}{ Ethaline } & 0.014 at $25^{\circ} \mathrm{C}$ & \multirow{2}{*}{ Tafel plots, [61] } \\
\hline & & 0.23 at $75^{\circ} \mathrm{C}$ & \\
\hline & \multirow{2}{*}{ Glyceline } & $8 \times 10^{-3}$ at $25^{\circ} \mathrm{C}$ & \multirow{2}{*}{ Tafel plots, [61] } \\
\hline & & 0.11 at $75^{\circ} \mathrm{C}$ & \\
\hline & ChCl-malonic acid & 0.4 at $25^{\circ} \mathrm{C}$ & Tafel plots [61] \\
\hline & cnce-matomic acto & 22.7 at $75^{\circ} \mathrm{C}$ & Іатеl plots, [61] \\
\hline $\begin{array}{c}\text { Aluminum alloys AA2024 } \\
\text { and AA6065 }\end{array}$ & Reline & 0.4 at $60^{\circ} \mathrm{C}$ & $\begin{array}{c}\text { Inductively coupled plasma optical } \\
\text { Emission spectroscopy, [60] }\end{array}$ \\
\hline
\end{tabular}

Extremely low corrosion rates for mild steel, $\mathrm{Ni}$ and $\mathrm{Al}$ in reline, ethaline, and glyceline: 1.9 to $5.02 \mu$ year $^{-1}$

Tafel plots, [48] Very slow reaction of AZ31B Mg alloy in ethaline, at temperatures up to $85^{\circ} \mathrm{C}$

Cholinium cation, being the representative of quaternary ammonium cations, is extremely stable toward the electroreduction, even at very negative electrode potentials [65]. Pure ethylene glycol (a constituent of ethaline) is almost inert even to reactive metals like magnesium [66]. As concerning urea (a constituent of reline), although the molten urea is a very versatile solvent that dissolves the majority of inorganic chemicals [67], the data on its corrosivity are very scarce. Yet, it is known from the research in urea production plants that the pure molten urea is not corrosive to stainless steels [68] and in addition, it has been used as a supporting electrolyte with a wide electrochemical window [69]. This brief summary shows that, indeed, the pure organics used for preparing the most common DESs, are not capable of metal oxidation. 
The second important reason for the low corrosivity of choline chloride-based DESs is probably the corrosion inhibiting nature of the raw compounds. Like most organics, the choline cation and the common hydrogen bond donors should be easily adsorbed onto a metal surface, which is the main prerequisite for the inhibition of the corrosion process by blocking the anodic and/or cathodic sites. Consequently, the literature on the application of quaternary ammonium ions [70], choline based salts [71], choline based ionic liquids [72], urea [73], ethylene glycol [66, 74], alcohols in general [75], etc., as corrosion inhibitors in aqueous media, is extensive.

In [60], very low corrosion of AA2024-T6 and AA6065-T6 alloys in reline was ascribed to the adsorption of choline cation or urea molecules on the metal surface, where one or both of these species constitute the first liquid layer in contact with $\mathrm{Al}_{2} \mathrm{O}_{3}$ passive film, thus separating and protecting it from the $\mathrm{Cl}^{-}$anions. It was well documented for various DESs (choline chloride with ethylene glycol, 1,2- ethanediol, 1,2-propanediol, 1,3-propanediol, urea or thiourea) that at negative and open circuit electrode potential, the choline cations and HBD molecules occupy the first layer of adsorbate at the metal surface, whereas at a positive potential, the $\mathrm{Cl}^{-}$anion is adsorbed $[76,77]$. The mechanism of reline adsorption at various $2 \mathrm{D}$ nanomaterials was studied using molecular simulation methods [78]. Independently on the material used as a substrate, the number density profiles showed that the first adsorbed layer mainly consisted of urea molecules, while the number of $\mathrm{Cl}^{-}$ions was significantly low, as presented in Figure 4 [78].
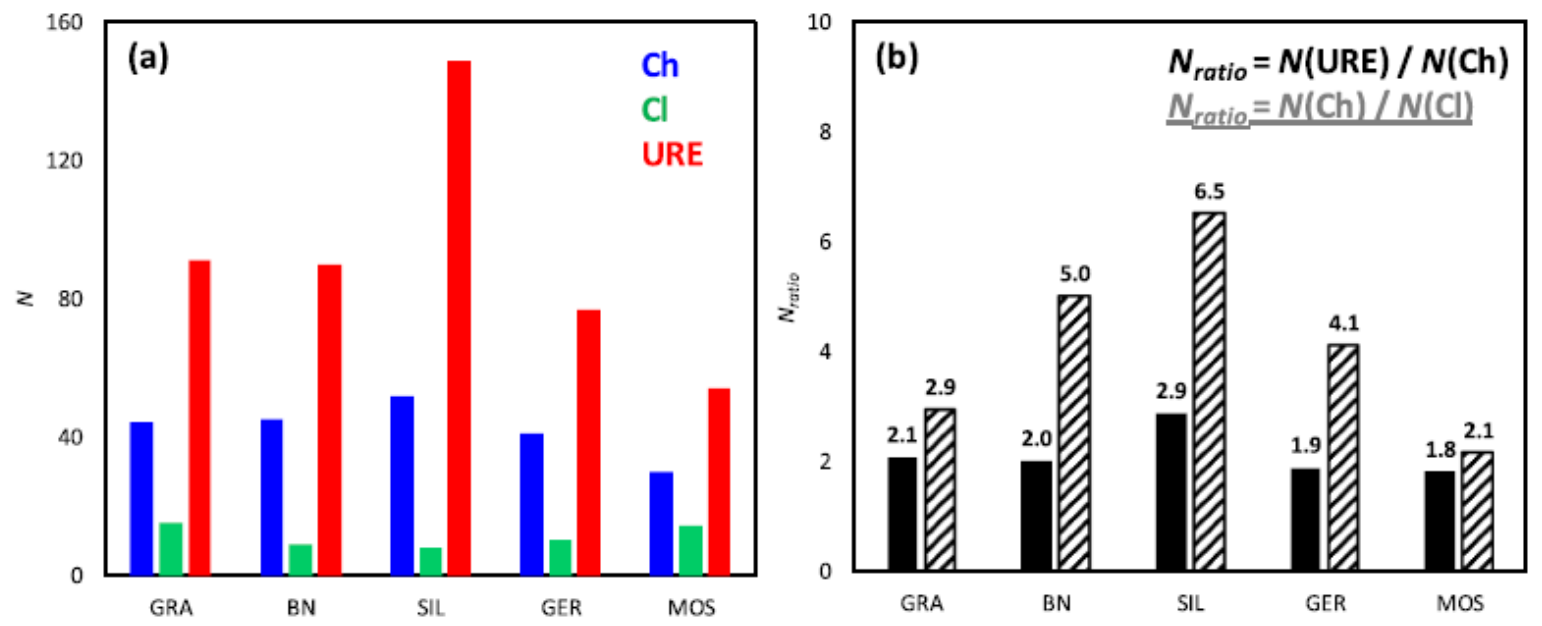

Figure 4. Number of molecules, $N$, in the first adsorbed layer for reline adsorbed on graphene, boron nitride, silicene, germanene, and molybdenum disulfide [78]

Reprinted with permission from ref. [78] copyright (2020), American Chemical Society

Finally, as is the case in other organic media, an important factor of the metal corrosion rate in DES, may be the DES high viscosity or low electrical conductivity. For example, in the case of $\mathrm{Zn}$ corrosion in $\mathrm{HCl}$-containing representatives of alcohols, ketones, esters, ethers, aromatics and chlorinated hydrocarbons, the viscosity was singled out as the decisive factor in the corrosion rate since it plays an important part in the transport of the oxidation agent and corrosion products [79]. On the contrary, in the same investigation and same media, for other metals under study (Fe, Al and stainless steel), the electrolytic conductivity of the solvents showed the most notable influence on the corrosion rate. It was concluded that the conductivity of around $10 \mathrm{mS} \mathrm{cm}^{-1}$ represents a threshold value below which the corrosion process is considerably retarded, because the corrosion mechanism changes from electrolytic to non-electrolytic. The industrial application of organic media with conductivity lower than the listed threshold value would enable the employment of construction materials that are lower in price without fear of corrosion [79]. 
It is very important to draw the parallel between the described findings in organic media and the case of DESs, bearing in mind the high viscosity and low electrical conductivity of the majority of DESs, as illustrated in Table 4. For instance, the high reline viscosity and low diffusivity of species in this liquid were assumed to be an important factor in Al-oxide passive film's stability at the Al-alloys in reline. Namely, the passive layer at the AA2024-T6 and AA6065 alloy surfaces remained intact even after 35 days of exposure to reline at $60{ }^{\circ} \mathrm{C}$ [60]. It was concluded that the pitting corrosion, even if it occurs at some point, will be terminated due to the significant mass transport limitation in a viscous medium because the diffusion of metal cations within the pit is necessary for a stable pit formation.

Although the conductivity of DESs with common HBDs listed in the table is notably higher than the conductivity of molecular solvents like ethylene glycol and glycerol, it is still well below the critical value of $10 \mathrm{mS} \mathrm{cm}^{-1}$.

Table 4. Viscosity and electrical conductivity of several DESs, some ionic liquids, and some molecular solvents at $298 \mathrm{~K}$

\begin{tabular}{|c|c|c|c|}
\hline Solvent & Viscosity, $\mathrm{cP}$ & Conductivity, $\mathrm{mS} \mathrm{cm}^{-1}$ & Reference \\
\hline ChCl-malonic acid & 721 & 0.55 & [4] \\
\hline ChCl-urea DES & 632 & 0.75 & [4] \\
\hline ChCl-glycerol & 376 & 1.05 & [4] \\
\hline ChCl-ethylene glycol DES & 36 & 7.61 & [4] \\
\hline $\mathrm{C}_{4} \mathrm{mimBF}_{4}$ ionic liquid & 115 & 3.5 & [4] \\
\hline Glycerol & 967 & $510^{-5}$ & {$[80]$} \\
\hline Ethylene glycol & 16.1 & $1.410^{-4}$ & [81] \\
\hline
\end{tabular}

\section{Effect of water content}

Since choline chloride and typical HBDs in DESs (amides, alcohols, polyols, carboxylic acids, etc.) are very hygroscopic substances, a highly hydrophilic behaviour of most choline chloride-based DESs is expected [82]. As an illustration, reline contains $2500 \mathrm{ppm}$ water even after a drying process conducted in a vacuum oven at $353 \mathrm{~K}$ over $24 \mathrm{~h}$, and it can absorb atmospheric moisture up to a water concentration of $40 \mathrm{wt} . \%$ [83]. Similarly, the as-prepared ethaline contained $2.4 \mathrm{wt} . \%$ water even after thorough drying of precursor materials, and after two weeks in the open air, the water content reached $14.3 \mathrm{wt} . \%$ [82].

In general, water in DES decreases its kinematic viscosity (Figure 5), increases its electrical conductivity, and notably narrows its electrochemical window [82,84], and all these factors contribute to the increase in the corrosion processes rate. Consequently, it was shown in [85] that the corrosion of mild steel in ethaline and reline is significantly enhanced even with the addition of only 10 wt.\% of water.

Very similar observations may be found in numerous researches of the water effect on the corrosivity of ionic liquids. When the corrosion behaviour of carbon steel, austenitic stainless steel, nickelbased alloy, copper, brass and AIMg3 alloy was examined in seven ionic liquids with different chemical structures, the addition of only $10 \%$ of water increased the corrosivity of all ionic liquids significantly [87]. The increased corrosion rate with water addition of up to $8 \mathrm{wt} . \%$ was also measured for the case of Mg alloys in 1-butyl-3-methylimidazolium trifluoromethyl sulfonate ionic liquid [88].

The water effect on the metal corrosion rate in ionic liquids and deep eutectic solvents was ascribed to the increased solubility of oxygen as a cathodic species in the corrosion mechanism, higher diffusivity of oxygen, and the easier removal of corrosion products $[85,89]$. Moreover, it is known that 
the presence of water in an ionic liquid can cause anion hydrolysis, increasing electrolyte aggressiveness [89]. This should also be held in mind when a particular DES is selected for technical applications.

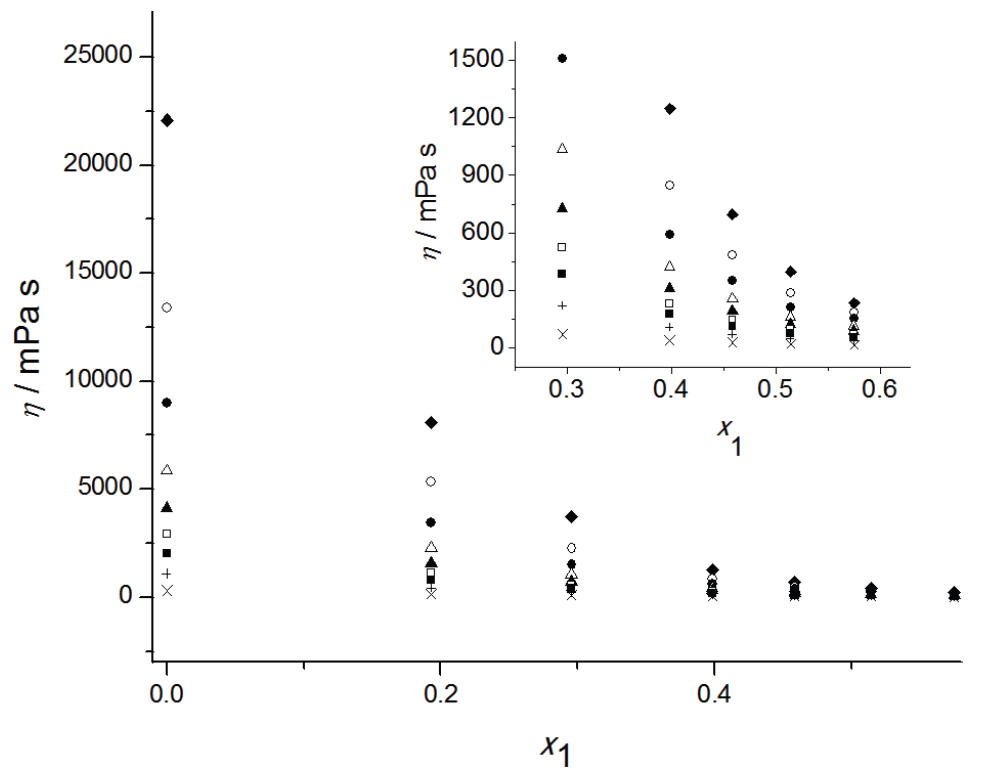

Figure 5. Experimental values of viscosity vs. water mole fraction for the choline chloride $+D L-$

malic acid DES, where symbols refer to experimental data points at several temperatures:

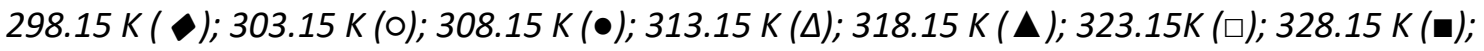

$338.15 K(+) ; 348.15 K(\Delta) ; 358.15 K(4)$ and $363.15 K(x)$ [86]

Reprinted with permission from ref. [86] copyright (2017), Serbian Chemical Society

According to the previous knowledge, it may be stated that the appropriate DES handling, storage, and water removal strategies should be developed to minimize the water content in DES in commercial applications.

Finally, when the future application of these types of electrolytes at an industrial scale is taken into account, it should be held in mind that even if the corrosion rates of various metals in DESs are low, future studies should focus on the long exposure to the DESs, which is characteristics of the real-life exploitation. Only a few of the cited studies in this review report the results from the prolonged contact of metals with DESs. In [56], the behaviour of the mild steel was monitored for 30 days of exposure to ethaline and reline, but it was observed that the most significant changes on the sample surface occurred on the first day of immersion. In the other example, the corrosion of Al alloys in reline was monitored for 36 days and it was concluded that the resistance of the passive layer steadily increased over the immersion time [60].

\section{Conclusions}

In spite of the fact that the term "deep eutectic solvent" may be attributed to as many as $10^{6}-10^{8}$ various mixtures, the corrosion problem has been raised for a remarkably low number of DESs until now. A comprehensive literature data is nowadays available exclusively for traditional DESs containing choline chloride as their component, so these sources were the focus of the current review. One of the first and still actual applications of DESs has been the dissolution of various metal salts in electroplating, anodic polishing, and metal extraction/recycling by electrolysis due to the very strong solvating power of DESs. However, as this review clearly shows for various metals and DESs, when it comes to the dissolution of metals or alloys in their reduced $\left(\mathrm{M}^{0}\right)$ state, the solvating power of DESs shows to be very low, resulting in strikingly low corrosion rates. 
This article recognizes the most distinguishing causative factors for the low DES corrosivity, and these are the absence of the oxidizing agents (apart from hydrogen ion, oxygen and water), the inhibiting role of organic DES components, and physical properties that do not allow the rapid corrosion process to occur or enhance the metal passivation process.

Yet, concerning the water impurity influence on their corrosivity, DESs are no different from the majority of other organic solvents or ionic liquids: the increase in water content notably increases the DES aggressiveness. If corrosion problems are to be avoided, strategies to minimize the water content in DES should be applied.

Acknowledgement: This research was financed by the Ministry of Education, Science and Technological Development of the Republic of Serbia (Contract No. 451-03-9/2021-14/200135).

\section{References}

[1] A. P. Abbott, G. Capper, D. L. Davies, R. K. Rasheed, V. Tambyrajah, Chemical Communications 0 (2003) 70-71. https://doi.org/10.1039/B210714G

[2] B.B. Hansen, S. Spittle, B. A. Ragauskas, M. Dadmun, T.A. Zawodzinski, G.A Chen, D. Poe, Y. Zhang, J. M. Klein, A. Horton, L. Adhikari, T. Zelovich, B. W. Doherty, B. Gurkan, E. J. Maginn, . Baker, M. E. Tuckerman, R. F. Savinell, J. R. Sangoro, Chemical Reviews 121 (2021) 12321285. https://dx.doi.org/10.1021/acs.chemrev.0c00385

[3] A. P. Abbott, D. Boothby, G. Capper, D. L. Davies, R. K. Rasheed, Journal of the American Chemical Society 126 (2004) 9142-9147. https://doi.org/10.1021/ja048266j

[4] E. L. Smith, A. P. Abbott, K. S. Ryder, Chemical Reviews 114 (2014) 11060-11082. https://doi.org/10.1021/cr300162p

[5] K. Radošević, M. Cvjetko Bubalo, V. G. Srček, D. Grgas, D. Landeka, T. L. Dragičević, I. Radojčić Redovniković, Ecotoxicology and Environmental Safety 112 (2015) 46-53.

https://doi.org/10.1016/i.ecoenv.2014.09.034

[6] B. Gurkan, H. Squire, E. Pentzer, Journal of Physical Chemistry Letters 10 (2019) 7956-7964. https://doi.org/10.1021/acs.jpclett.9b01980

[7] G. R. Jenkin, A. Z. Al-Bassam, R. C. Harris, A. P. Abbott, D. J. Smith, D. A. Holwell, R. J. Chapman, C .J. Stanley, Minerals Engineering 87 (2016) 18-24.

https://doi.org/10.1016/i.mineng.2015.09.026

[8] A. P. Abbott, K. J. McKenzie, K. S. Ryder, ACS Symposium Series 975 (2007) 186-197. https://doi.org/10.1021/bk-2007-0975.ch013

[9] P. Sebastian, M. I. I. Giannotti, E. Gómez, J. M. Feliu, ACS Applied Energy Materials 1 (2018) 1016-1028. https://doi.org/10.1021/acsaem.7b00177

[10] F. S. Oliveira, A. B. Pereiro, L. P. Rebelo, I. M. Marrucho, Green Chemistry 15 (2013) 13261330. https://doi.org/10.1039/c3gc37030e

[11] N. Schaeffer, M. A. Martins, C. M. Neves, S. P. Pinho, J. A. Coutinho, Chemical Communications 54 (2018) 8104-8107. https://doi.org/10.1039/c8cc04152k

[12] S. Sarmad, J. P. Mikkola, X. Ji, ChemSusChem 10 (2017) 324-352. https://doi.org/10.1002/cssc.201600987

[13] M. Chakrabarti, F. Mjalli, I. Alnashef, M. Hashim, M. Hussain, L. Bahadori, C. Low, Renewable Sustainable Energy Reviews 30 (2014) 254-270. https://doi.org/10.1016/i.rser.2013.10.004

[14] H. D. Jhong, D. S. H. Wong, C. C. Wan, Y. Y. Wang, T. C. Wei, Electrochemistry Communications 11 (2009) 209-211. https://doi.org/10.1016/i.elecom.2008.11.001

[15] M. Pätzold, S. Siebenhaller, S. Kara, A. Liese, C. Syldatk, D. Holtmann, Trends in Biotechnology 37 (2019) 943-959. https://doi.org/10.1016/i.tibtech.2019.03.007

[16] H. Zhao, G. A. Baker, Journal of Chemical Technology and Biotechnology 88 (2013) 3-12. https://doi.org/10.1002/ictb.3935 
[17] K. D. O. Vigier, G. Chatel, F. Jérôme, ChemCatChem 7 (2015) 1250-1260. https://doi.org/10.1002/cctc.201500134

[18] R. Esquembre, J. M. Sanz, J. G. Wall, F. del Monte, C. R. Mateo, M. L. Ferrer, Physical Chemistry Chemical Physics 15 (2013) 11248-11256. https://doi.org/10.1039/c3cp44299c

[19] I. Mamajanov, A. E. Engelhart, H. D. Bean, N. V. Hud, Angewandte Chemie International Edition 49 (2010) 6310-6314. https://doi.org/10.1002/anie.201001561

[20] M. Zakrewsky, A. Banerjee, S. Apte, T. Kern, M. Jones, R. Sesto, A. Koppisch, D. Fox, S. Mitragotri, Advanced Healthcare Materials 5 (2016) 1282-1289. https://doi.org/10.1002/adhm.201600086

[21] Y. Huang, F. Shen, J. La, G. Luo, J. Lai, C. Liu, G. Chu, Particulate Science and Technology 31 (2013) 81-84. https://doi.org/10.1080/02726351.2011.648823

[22] X. Cunying, W. Qing, Y. Hua, J. Li, Journal of Solid State Electrochemistry 18 (2014) 21492155. https://doi.org/10.1007/s10008-014-2468-1

[23] R. Bernasconi, G. Panzeri, A. Accogli, F. Liberale, L. Nobili, L. Magagnin, Electrodeposition from deep eutectic solvents in: Progress and Developments in lonic Liquids, IntechOpen (2017) 235-261. https://doi.org/10.5772/64935

[24] A. V. Rudnev, Russian Chemical Reviews 89 (2020) 1463-1482. https://doi.org/10.1070/RCR4970

[25] A. P. Abbott, K. J. McKenzie, Physical Chemistry Chemical Physics 8 (2006) 4265-4279. https://doi.org/10.1039/B607329H

[26] V. S. Cvetkovic, N. M. Vukicevic, N. Jovicevic, J. S. Stevanovic, J. N. Jovicevic, Transactions of Nonferrous Metals Society of China 30 (2020) 823-834. https://doi.org/10.1016/S10036326(20)65257-8

[27] Y. H. You, C. Gu, X. Wang, J. Tu, Surface and Coatings Technology 206 (2012) 3632-3638. https://doi.org/10.1016/i.surfcoat.2012.03.001

[28] T. A. Green, P. Valverde, S. Roy, Journal of the Electrochemical Society 165 (2018) D313D320. https://doi.org/10.1149/2.0371809jes

[29] T. A. Green, X. Su, S. Roy, ECS Transactions 77 (2017) 1247-1253. https://doi.org/ 10.1149/07711.1247ecs

[30] S. Ghosh, S. Roy, Surface and Coatings Technology 238 (2014) 165-173. https://doi.org/10.1016/i.surfcoat.2013.10.069

[31] P. Valverde, T. Green, S. Roy, ECS Transactions 77 (2017) 859-864. https://doi.org/10.1149/07711.0859ecst

[32] M. Bučko, D. Culliton, A. J. Betts, J. B. Bajat, Transactions of the IMF 95 (2017) 60-64. https://doi.org/10.1080/00202967.2017.1255412

[33] E. Gómez, P. Cojocaru, L. Magagnin, E. Valles, Journal of Electroanalytical Chemistry 658 (2011) 18-24. https://doi.org/10.1016/i.jelechem.2011.04.015

[34] P. Cojocaru, L. Magagnin, E. Gomez, E. Vallés, Materials Letters 65 (2011) 3597-3600. https://doi.org/10.1016/i.matlet.2011.08.003

[35] M. Steichen, M. Thomassey, S. Siebentritt, P. J. Dale, Physical Chemistry Chemical Physics 13 (2011) 4292-4302. https://doi.org/10.1039/C0CP01408G

[36] P. Guillamat, M. Cortés, E. Vallés, E. Gómez, Surface and Coatings Technology 206 (2012) 4439-4448. https://doi.org/10.1016/i.surfcoat.2012.04.093

[37] A. P. Abbott, J. C. Barron, K. S. Ryder, D. Wilson, Chemistry A European Journal 13 (2007) 6495-6501. https://doi.org/10.1002/chem.200601738

[38] T. Beyersdorff, T. J. S. Schubert, U. Welz-Biermann, W. Pitner, A. P. Abbott, K. J. McKenzie, K. S. Ryder, in D. R. MacFarlane, A. P. Abbott, (eds.), Electrodeposition from Ionic Liquids, WileyVCH, Weinheim, Germany, 2008, p. 15. https://doi.org/10.1002/9783527682706 
[39] E. Heitz, Corrosion of metals in organic solvents, in M.G. Fontana et al. (eds.), Advances in Corrosion Science and Technology, Plenum Press, New York, USA, 1974, p. 149. https://doi.org/10.1007/978-1-4615-9059-0 3

[40] A. P. Abbott, S. S. M. Alabdullah, A. Y. M. Al-Murshedi, K.S. Ryder, Faraday Discussions 206 (2018) 365-377. https://doi.org/10.1039/c7fd00153c

[41] T. Lemaoui, F. Abu Hatab, A. S. Darwish, A. Attoui, N. E. H. Hammoudi, G. Almustafa, M. Benaicha, Y. Benguerba, I. M. Alnashef, ACS Sustainable Chemical Engineering 9 (2021) 57835808. https://doi.org/10.1021/acssuschemeng.0c07367

[42] E. Heitz', C. Kyriazis, Industrial \& Engineering Chemistry Research 17 (1978) 37-41. https://doi.org/10.1021/i360065a011

[43] S. S. Alabdullah, $p H$ measurements in ionic liquids, Doctoral Thesis, University of Leicester, 2018.

[44] A. Mitar, M. Panić, J. Prlić Kardum, J. Halambek, A. Sander, K. Zagajski Kučan, I. Radojčić Redovniković, K. Radošević, Chemical and Biochemical Engineering Quarterly 33 (2019) 1-18. https://doi.org/10.15255/CABEQ.2018.1454

[45] F. S. Mjalli, O.U. Ahmed, Asia-Pacific Journal of Chemical Engineering 12 (2017) 313-320. https://doi.org/10.1002/apj.2074

[46] F. S. Mjalli, O. U. Ahmed, Korean Journal of Chemical Engineering 33 (2016) 337-343. https://doi.org/10.1007/s11814-015-0134-7

[47] D. Shah, F. S. Mjalli, Physical Chemistry Chemical Physics 16 (2014) 23900-23907. https://doi.org/10.1039/C4CP02600D

[48] A. P. Abbott, E. I. Ahmed, R. C. Harris, K. S. Ryder, Green Chemistry 16 (2014) 4156-4161. https://doi.org/10.1039/C4GC00952E

[49] I. M. Pateli, D. Thompson, S. S. M. Alabdullah, A. P. Abbott, G. R. T. Jenkin, J. M. Hartley, Green Chemistry 22 (2020) 5476-5486. https://doi.org/10.1039/D0GC02023K

[50] E. McCafferty, Corrosion Science 45 (2003) 1421-1438. https://doi.org/10.1016/S0010938X(02)00231-7

[51] J. Soltis, Corrosion Science 90 (2015) 5-22. https://doi.org/10.1016/i.corsci.2014.10.006

[52] X. Li, K. Binnemans, Chemical Reviews 121 (2021) 4506-4530. https://doi.org/10.1021/acs.chemrev.0c00917

[53] Y. Nakao, Journal of the Chemical Society, Chemical Communications 5 (1992) 426-427. https://doi.org/10.1039/C39920000426

[54] G. Kear, B. D. Barker, F. C. Walsh, Corrosion Science 46 (2004) 109-135. https://doi.org/10.1016/S0010-938X(02)00257-3

[55] F. R. Pérez, C. A. Barrero, A. R. H. Walker, K. E. García, K. Nomura, Materials Chemistry and Physics 117 (2009) 214-223. https://doi.org/10.1016/i.matchemphys.2009.05.045

[56] A. A. Kityk, Y. D. Rublova, A. Kelm, V. V. Malyshev, N. G. Bannyk, I. Flis-Kabulska, Journal of Electroanalytical Chemistry 823 (2018) 234-244. https://doi.org/10.1016/i.jelechem.$\underline{2018.06 .018}$

[57] J. M. Hartley, C. M. Ip, G. C. H. Forrest, K. Singh, S. J. Gurman, K. S. Ryder, A. P. Abbott, G. Frisch, Inorganic Chemistry 53 (2014) 6280-6288. https://doi.org/10.1021/ic500824r

[58] J. L. Barriada, A. D. Tappin, E. Hywel Evans, E. P. Achterberg, TrAC Trends in Analytical Chemistry 26 (2007) 809-817. https://doi.org/10.1016/i.trac.2007.06.004

[59] A. P. Abbott, G. Frisch, S. J. Gurman, A. R. Hillman, J. Hartley, F. Holyoak, K. S. Ryder, Chemical Communications 47 (2011) 10031-10033. https://doi.org/10.1039/C1CC13616J

[60] M. Bucko, A. C. Bastos, M. G. S. Ferreira, J. B. Bajat, Electrochimica Acta 357 (2020) 136861. https://doi.org/10.1016/i.electacta.2020.136861

[61] T. H. Ibrahim, R. Alhasan, M. Bedrelzaman, M. A. Sabri, N. A. Jabbar, F. S. Mjalli, International Journal of Electrochemical Science 14 (2019) 8450-8469. https://doi.org/10.20964/2019.09.27 
[62] J. Tang, C. Xu, X. Zhu, H. Liu, X. Wang, M. Huang, Y. Hua, Q. Zhang, Y. Li, Journal of The Electrochemical Society 165 (2018) E406-E411. https://doi.org/10.1149/2.0091810jes

[63] M. L. Doche, A. Mandroyan, M. Mourad-Mahmoud, V. Moutarlier, J. Y. Hihn, Chemical Engineering and Processing: Process Intensification 121 (2017) 90-96.

https://doi.org/10.1016/i.cep.2017.08.006

[64] J. Zhang, C. Gu, W. Yan, J. Tu, X. Ding, Surface and Coatings Technology 344 (2018) 702-709. https://doi.org/10.1016/i.surfcoat.2018.04.004

[65] G. H. Lane, Electrochimica Acta 83 (2012) 513-528. https://doi.org/10.1016/i.electacta.$\underline{2012.08 .046}$

[66] G. Song, D. StJohn, Corrosion Science 46 (2004) 1381-1399. https://doi.org/10.1016/i.corsci.$\underline{2003.10 .008}$

[67] R. Clark, Nature 168 (1951) 876-876. https://doi.org/10.1038/168876a0

[68] D. E. Nichols, D. T. Nguyen, M. M. Norton, B. R. Parker, L. E. Daniels, $202^{\text {nd }}$ National Meeting of the American Chemical Society, The effect of conditioning agents on the corrosive properties of molten urea, New York, USA, 1991, p. 1

[69] H. Liang, H. Li, Z. Wang, F. Wu, L. Chen, X. Huang, The Journal of Physical Chemistry B 105 (2001) 9966-9969. https://doi.org/10.1021/ip0119779

[70] R. J. Meakins, Journal of Applied Chemistry 13 (1963) 339-345. https://doi.org/10.1002/ictb.$\underline{5010130803}$

[71] R. Solmaz, Corrosion Science 81 (2014) 75-84. https://doi.org/10.1016/j.corsci.2013.12.006

[72] C. Verma, I. B. Obot, I. Bahadur, E.-S. M. Sherif, E. E. Ebenso, Applied Surface Science 457 (2018) 134-149. https://doi.org/10.1016/i.apsusc.2018.06.035

[73] S. M. Abd El Haleem, S. Abd El Wanees, E. E. Abd El Aal, A. Farouk, Corrosion Science 68 (2013) 1-13. https://doi.org/10.1016/i.corsci.2012.03.021

[74] B. Widyanto, I. Gede Bagus Eka Suputra Wiguna, Heliyon 5 (2019) e02006. https://doi.org/10.1016/i.heliyon.2019.e02006

[75] D. Jayaperumal, Materials Chemistry and Physics 119 (3) 478-484. https://doi.org/10.1016/i.matchemphys.2009.09.028

[76] J. Wu, R. Zhou, P.M. Radjenovic, S. Liu, D. Wu, J. Li, B. Mao, J. Yan, Electrochimica Acta 390 (2021) 138859. https://doi.org/10.1016/i.electacta.2021.138859

[77] R. Costa, M. Figueiredo, C. M. Pereira, F. Silva, Electrochimica Acta 55 (2010) 8916-8920. https://doi.org/10.1016/i.electacta.2010.07.070

[78] S. Rozas, M. Atilhan, S. Aparicio, The Journal of Physical Chemistry B 124 (2020) 1197-1206. https://doi.org/10.1021/acs.jpclett.9b01980

[79] P. Hronsky, Corrosion 37 (1981) 161-170. https://doi.org/10.5006/1.3622160

[80] S. R. Gregory, Physical properties of glycerine, in E. Jungermann, N.O.V. Sonntag (eds.) Glycerine A Key Cosmetic Ingredient, CRC Press, Boca Raton, USA, 1991, p. 111. https://doi.org/10.1201/9780203753071

[81] V. V. Loskutov, G. N. Kosova, Russian Journal of Physical Chemistry A 93 (2019) 260-264. https://doi.org/10.1134/S003602441902016X

[82] J. Raymund Brusas, E. M. B. Dela Pena, Journal of Electrochemical Science and Technology (2021) Ahead of print. https://doi.org/10.33961/jecst.2020.01522

[83] D. Cuiling, B. Zhao, C. Xiao-Bo, N. Birbilis, H. Yang, Scientific Reports 6 (2016) 29225-29239. https://doi.org/10.1038/srep29225

[84] M. Bucko, S. Roy, P. Valverde-Armas, A. Onjia, A. C. Bastos, J. B. Bajat, Journal of The Electrochemical Society 165 (16) (2018) H1059-H1065. https://doi.org/10.1149/2.0921816jes]

[85] Y. D. Rublova, A. A. Kityk, N. G. Bannyk, V. S. Protsenko, F. I. Danilov, Materials Today: Proceedings 6 (2019) 232-236. https://doi.org/10.1016/j.matpr.2018.10.099 
[86] J. M. Vuksanović, N. M. Todorović, M. Lj. Kijevčanin, S. P. Šerbanović, I. R. Radović, Journal of the Serbian Chemical Society 82 (2017) 1287-1302. https://doi.org/10.2298/JSC170316054V

[87] M. Uerdingen, C. Treber, M. Balser, G. Schmitt, C. Werner, Green Chemistry 7 (2005) 321325. https://doi.org/10.1039/B419320M

[88] A. Shkurankov, S. Z. El Abedin, F. Endres, Australian Journal of Chemistry 60 (2007) 35-42. https://doi.org/10.1071/CH06305

[89] S. Noori, M. V. Diamanti, M. P. Pedeferri, A. Brenna, M. Ormellese, Materials and Corrosion 69 (2018) 1658-1668. https://doi.org/10.1002/maco.201810215

(C)2021 by the authors; licensee IAPC, Zagreb, Croatia. This article is an open-access article distributed under the terms and conditions of the Creative Commons Attribution license (https://creativecommons.org/licenses/by/4.0/) 